\title{
Diskrete, aber gefährliche Folge eines Zeckenstichs
}

\section{Das scharf begrenzte rötliche Knötchen hätte auch ein Insek- tenstich sein können. Die Anam- nese führte jedoch auf eine an- dere Fährte: Der Fünfjährige war in den Ferien im Borrelienrisiko- gebiet Niederbayern.}

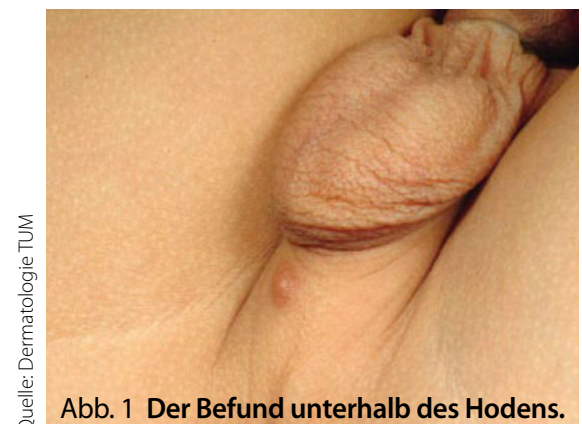

— Die Mutter des Fünfjährigen berichtete über eine seit ca. zwei Monaten bestehende, diskret juckende, rötliche Hautveränderung unterhalb des Skrotums. Ein Zeckenstich war nicht erinnerlich, jedoch hatte die Familie vier Monate zuvor Urlaub in Niederbayern gemacht.

Bei Inspektion fand sich ein $1 \mathrm{~cm}$ durchmessender, erythematös-livide verfärbter, scharf begrenzter, relativ derb zu tastender Knoten perineal (Abb. 1). Die weitere körperliche Untersuchung inklusive Lymphknotenstatus war unauffällig.
Die Borrelien-Serologie ergab positive Ergebnisse für IgM und hochpositive Ergebnisse für IgG sowohl im ELISA als auch im Immunoblot.

Die Therapie erfolgte oral mit Amoxicillin $50 \mathrm{mg} / \mathrm{kg} /$ die über drei Wochen. Darunter kam es zu einer deutlichen Rückbildung der Hautveränderung sowie der serologischen Befunde. Bereits nach zwei Monaten zeigte sich im ELISA ein negativer Befund für IgM sowie eine deutliche Abnahme des IgG von 45,01 auf 31,04. Bei serologischer Kontrolle nach eineinhalb Jahren zeigte sich im Immunoblot eine deutliche Abnahme der positiven Banden für IgG. Im ELISA war die IgG-Antikörperkonzentration auf 19,04 abgesunken (Normbereich VE 9-11).

\section{Diskussion}

Die Lymphadenosis cutis benigna macht bei Kindern ca. 7\%, bei Erwachsenen ca. 3\% der Erstmanifestation einer BorrelienFrühinfektion aus. Ursächlich liegt eine Abwehrreaktion auf Borrelien in der Haut vor. Das Borrelienlymphozytom wird bei solitärem Auftreten ohne Allgemeinsymptome dem Stadium I der Borreliose (lokalisierte Frühinfektion) zugeordnet. Ein Auftreten multipler Lymphozytome, auch die Kombination mit einem Erythema migrans und Allgemeinsymptomen in späteren Stadien ist möglich.

Prädilektionsstellen sind Ohrläppchen, Mamillen und Skrotum, i.d. R. am Ort des
Zeckenstichs. Wegweisend sind Anamnese, klinisches Erscheinungsbild sowie serologische Untersuchungen. Auf histologische Untersuchungen kann bei Kindern meist verzichtet werden; es findet sich ein polymorphes, lymphohistiozytäres Infiltrat, v. a. aus polyklonalen B-Zellen mit umgebenden T-Zellen. Häufig finden sich Plasmazellen und eosinophile Granulozyten sowie reaktive Keimzentren. Hautbiopsate aus Borrelienlymphozytomen zeigen i.d.R. positive PCR-Ergebnisse für Borrelien-DNA, in seltenen Fällen gelingt eine Isolierung lebender Borrelien.

Therapeutisch stehen bei Kindern unter neun Jahren Amoxicillin (s.o.) und Cefuroximaxetil (20-30 mg/kg/die über 2-3 Wochen) sowie Azithromycin (5-10 mg/die, 5-10 Tage) zur Verfügung. Ab dem neunten Lebensjahr kann Doxycyclin (2-4 mg/kg) verabreicht werden. Die Hautveränderungen heilen unter Therapie i. d. R. innerhalb von zwei Monaten ab.

\section{Für die Verfasser:}

Dr. med. Benedetta Belloni Klinik und Poliklinik für Dermatologie und Allergologie am Biederstein, TU München Biedersteiner Str. 29, D-80802 München E-Mail: benedetta.belloni@Irz.tum.de

\section{Keywords}

5-Yr. Old with Borrelial Lymphocytoma

Lymphocytoma cutis benigna Borrelia burgdorferi - Tick bite 